\title{
Economic evaluation of online computerised cognitive-behavioural therapy without support for depression in primary care: randomised trial ${ }^{\dagger}$
}

\author{
S. A. H. Gerhards, L. E. de Graaf, L. E. Jacobs, J. L. Severens, M. J. H. Huibers, A. Arntz, H. Riper, \\ G. Widdershoven, J. F. M. Metsemakers and S. M. A. A. Evers
}

\section{Background}

Evidence about the cost-effectiveness and cost utility of computerised cognitive-behavioural therapy (CCBT) is still limited. Recently, we compared the clinical effectiveness of unsupported, online CCBT with treatment as usual (TAU) and a combination of CCBT and TAU (CCBT plus TAU) for depression. The study is registered at the Netherlands Trial Register, part of the Dutch Cochrane Centre (ISRCTN47481236)

\section{Aims}

To assess the cost-effectiveness of CCBT compared with TAU and CCBT plus TAU.

\section{Method}

Costs, depression severity and quality of life were measured for 12 months. cost-effectiveness and cost-utility analyses were performed from a societal perspective. Uncertainty was dealt with by bootstrap replications and sensitivity analyses.

\section{Results}

Costs were lowest for the CCBT group. There are no significant group differences in effectiveness or quality of life. cost-utility and cost-effectiveness analyses tend to be in favour of CCBT.

\section{Conclusions}

On balance, CCBT constitutes the most efficient treatment strategy, although all treatments showed low adherence rates and modest improvements in depression and quality of life.

\section{Declaration of interest}

None.
Major depression is a common mental health problem in the general population ${ }^{1}$ and is associated with substantial reductions in quality of life. ${ }^{2,3}$ Cost-of-illness studies reveal that the economic burden of depression is considerable. ${ }^{4}$ However, many people with depression attending primary care do not receive the care they need. There is little evidence about the effectiveness of pharmacotherapy in patients with mild to moderate depression ${ }^{5}$ and psychological treatments in primary care are scarce and costly. Consequently, effective treatments like cognitive-behavioural therapy $(\mathrm{CBT})^{6,7}$ are not offered to all patients and many people with depression in primary care remain untreated. ${ }^{8}$ An effective, acceptable and feasible solution for such individuals might be computerised CBT (CCBT). ${ }^{9}$ The National Institute for Health and Clinical Excellence (NICE) recommended the use of two CCBT software programs for depression and anxiety, ${ }^{10}$ and these programs are now in use in England, Wales and Northern Ireland. In the Netherlands, an online CCBT program is currently being used as part of an ongoing implementation study (www.kleurjeleven.nl/). However, evidence about the costeffectiveness of CCBT is still limited. ${ }^{9}$ To our knowledge, only one study conducted an economic evaluation of CCBT for depression and it showed that CCBT (delivered on a personal computer in the general practice) can be highly cost-effective compared with usual care by a general practitioner (GP) in the UK setting. ${ }^{11}$ In a recent study, we compared the clinical effectiveness of unsupported, online CCBT (i.e. Colour Your Life) with treatment as usual (TAU) by a GP and a combination of both CCBT and TAU for depression (CCBT plus TAU). ${ }^{12}$ In the present study, we assess the cost-effectiveness of these interventions, focusing on the research question: for mild to moderate

†See editorial, pp. 257-258, this issue. depression, is CCBT compared with TAU or CCBT plus TAU preferable in terms of cost-effectiveness from a societal perspective? The Medical and Ethical Committee approved the study protocol. The study is registered at the Netherlands Trial Register, part of the Dutch Cochrane Centre (ISRCTN47481236)

\section{Method}

\section{Design and participants}

In a randomised trial, 303 participants were recruited from the general population by means of a large-scale internet-based screening in the South of the Netherlands. Inclusion criteria were: age 18-65; access to the internet at home (for optimal use of the CCBT program, a broad-band connection was required and not dial-up connection); at least mild to moderate depressive complaints (Beck Depression Inventory II (BDI-II) $)^{13}$ score $\geqslant 16$ ); duration of depressive complaints 3 months or more; no current psychological treatment for depression; no continuous antidepressant treatment for at least 3 months prior to entry; fluent in Dutch language; no alcohol and/ or drug dependence; and no severe psychiatric comorbidity (e.g. psychotic disorders). During a 1-year follow-up period, participants were asked to fill in monthly internet questionnaires. ${ }^{12,14}$

\section{Interventions}

Computerised CBT is based on the principles of cognitivebehavioural therapy. The CCBT program in our trial (named 'Colour Your Life' (in Dutch Kleur je Leven)) is an online, multimedia, interactive computer program for depression. The program consists of eight weekly sessions and a ninth booster session, including homework assignments and a 'mood diary'. No professional assistance was offered. Participants were able to 
use the program wherever they had a computer with internet access.

The GP is the major healthcare provider involved in the primary care of depression. In the Dutch healthcare system the GP is seen as a gatekeeper, and a key figure in the detection and treatment of depression. ${ }^{15}$ Participants who received TAU were advised to contact their own GP. After inclusion, the participants' GP received a letter about the individual's participation in the study. In the letter, the GP was advised to follow the depression guideline as described by the Dutch College of General Practitioners. Usual care as such can consist of four to five biweekly consultations in combination with antidepressant treatment if indicated. In practice, however, usual care is whatever the GP prescribes. ${ }^{16}$ Further details of the design of the trial, the interventions and the population can be found elsewhere. ${ }^{12,14}$

\section{Cost measures and valuation}

The economic evaluation was performed from the societal perspective. Costs were divided into the categories: healthcare sector costs, costs for patient and family, and productivity costs. ${ }^{17}$ As a result of the impact depression can have on a patient's overall health status, functioning and well-being, it is often not clear whether the healthcare use or productivity loss is depression related. We therefore included all related and unrelated costs in the analysis.

Healthcare costs were measured by means of a monthly healthcare use questionnaire. Participants were asked to report the volumes of psychological, paramedical, medical, paid and informal care, participation in self-help groups and alternative treatments received during the past month. Computerised CBT usage was based on computer-registered login data of the Colour Your Life program.

The patient and family costs consisted of travelling costs and lost time because of the intervention TAU and/or CCBT. The time spent by a participant on CCBT was tracked by means of the computer-registered login and logout data of the program. In the healthcare use questionnaire, the average duration of a GP consult was registered by the participant. For the time spent on psychological care received from a psychiatrist, we used a mean duration time of $30 \mathrm{~min}$ per session. The time spent with a psychologist, social-psychiatric nurse or other mental healthcare professional was valued by $45 \mathrm{~min}$ per session. We assumed that participants used the TAU and CCBT program outside working hours, and therefore valued their time costs as leisure time. The number of GP consultations provided information about the number of journeys to/from the GP, and was linked to the average travel distances to a GP in the Netherlands. ${ }^{18}$

Modules of the PROductivity and DISease Questionnaire (PRODISQ) were used to measure absenteeism, presenteeism and compensation mechanisms of absenteeism. ${ }^{19}$ Productivity costs were based on the outcomes of the PRODISQ, and calculated according to the friction cost method. ${ }^{18,20}$

Costs for computer and internet use were considered to be sunk costs and not included, as the inclusion criteria of the trial required that the participant has internet access at home. For the costs of Colour Your Life we included $€ 50$ per user for the whole program and the entire intervention period ( $\mathrm{H}$. Riper, personal communication, 2008). Dutch standard costs were used to value healthcare, patient and family, and productivity cost items. ${ }^{18}$ If for specific categories standard costs were unavailable, we used average tariffs. Medication costs were based on the Dutch Pharmacotherapeutic Compass. ${ }^{21}$ The standard costs and tariffs of healthcare practitioners were the integral costs, being all costs directly and indirectly attributable to the cost unit.
Costs are presented in Euros for the year 2007. Since the follow-up period lasted 1 year and no extrapolation over time was executed, discounting was not necessary. If needed, costs were indexed to the year 2007 by means of the consumer price indexes of the Dutch Central Bureau of Statistics.

\section{Outcome measures}

Depression severity was measured with the BDI-II. The total score is the sum of the 21 items with a range of 0 (no depression) to 63 (severe depression). There has been support for the construct validity and reliability of the BDI-II in various samples. ${ }^{13,22,23}$

Quality of life was measured with the EuroQol EQ-5D ${ }^{24}$ and the Short Form 6D (SF-6D). ${ }^{25}$ The EQ-5D consists of five health state dimensions (mobility, self-care, usual activity, pain/ discomfort and anxiety/depression) on which the respondent has to indicate his own health state. ${ }^{24}$ An advantage of the EuroQol is that it is short and that an overall utility score for population-based quality of life can be obtained, which facilitates comparisons with other interventions and health states in other disease areas. A utility refers to the preference that individuals or society may have for any particular set of health outcomes. It is indicated by a number between 0 (the worst imaginable condition: (death) and 1 (perfect health). ${ }^{17}$ Standardised value sets are available to calculate the utility based on the EQ-5D. Because many studies in the Netherlands and internationally use the UK tariff, this study used both the UK tariff and Dutch tariff to value generic quality of life. ${ }^{26,27}$

The SF-6D is a utility instrument based on the health-related quality of life questionnaire 36-item short-form Health Survey $(\mathrm{SF}-36){ }^{25}$ The utility score is derived from 11 items of the SF-36 and is composed of six dimensions of health (physical functioning, role limitations, social functioning, pain, mental health, and vitality). The SF-6D utilities were derived by means of the UK tariff. ${ }^{28,29}$

The EQ-5D and SF-6D utility scores were used to calculate the quality-adjusted life-year (QALY) during the follow-up period by adjusting the length of time between each measurement moment by the respective utility value for this period. ${ }^{17}$

\section{Analysis}

All available data were used. Only intermittent missing data were replaced by mean imputation using the outcomes from the previous and next measurement moment of the participant. Only 8 participants had intermittent missing data. In all these cases, the number of missing moments was limited to one moment. Data from individuals lost to follow-up were not imputed.

For each participant, volumes of care, travels, lost time for receiving care and lost productivity hours were multiplied by the prices determined for each cost item. Costs during the follow-up period were calculated as the cumulative costs per participant 12 months after baseline. The costs during the follow-up period of the three groups were compared by the non-parametric bootstrapping method with 95\% confidence intervals in percentiles. By bootstrapping, samples of the same size as the original data are drawn with replacement from the observed data. ${ }^{30}$ The quality of life and severity of depression outcomes during follow-up were compared between the three groups using ANOVA, Kruskall-Wallis and $\chi^{2}$-tests at the $P<0.05$ level. Baseline corrections for societal cost and QALY outcomes were performed by means of regression correction. ${ }^{31,32}$

The analysis consisted of a base-case cost-effectiveness and costutility analysis, and sensitivity analyses. In the base cases, the primary outcome measure for the cost-effectiveness analysis was change from baseline score of depression severity measured by the 
BDI-II at 12 months and for the cost-utility analysis the QALY at 12 months based on the EQ-5D using the UK tariff. Costs in the basecase analysis are calculated according to the societal perspective.

Uncertainty concerning the parameter estimates of the basecases was dealt with by the sensitivity analyses. ${ }^{17}$ In the sensitivity analyses, the correction method for baseline differences in costs and utilities was varied by using no correction. ${ }^{33,34}$ Other aspects of sensitivity analyses were: varying the time horizon of the costeffectiveness analysis from 12 to 6 months, varying the societal costs to healthcare costs, calculating productivity costs according to the human capital approach instead of the friction cost method, using the Dutch tariff to value the EQ-5D, varying the QALY outcome by using the SF-6D, and using the reliable change index of the BDI-II score as an outcome measure. For the reliable change we used the methodology of Jacobson \& Truax, ${ }^{33}$ which gives the proportion of participants with clinically meaningful changes in scores at 12 months (i.e. a decrease of at least 9 points on the BDI-II since baseline). As a result of uncertainty about the cost price of self-help online CCBT in the real world, this cost price was varied by estimating either one fixed price per package user ( $€ 5, € 50$ and $€ 150)$ and a price per lesson. Based on the price estimates per package, and an average number of five lessons completed by CCBT users, we varied this cost price by $€ 1, € 10$ and $€ 30$ per lesson.

As three strategies were being compared in this trial, an incremental approach was not feasible for analysing the costeffectiveness data. Therefore the net benefit was used to present the cost-utility results in monetary units for each strategy. The net benefit is calculated by valuing the utility outcome in monetary values using the threshold willingness-to-pay for a QALY, minus the costs of the interventions. ${ }^{34}$

Non-parametric bootstrap resampling techniques were used to explore uncertainty around estimates of cost-effectiveness and cost-utility derived from the study sample. ${ }^{30}$ For each bootstrap iteration, using a range of cost-effectiveness thresholds it was decided which strategy had the highest net benefit, and for all iterations it was calculated which strategy had the highest probability of being most efficient. The resulting decision uncertainty is represented graphically by a cost-effectiveness acceptability curve. ${ }^{17,35}$ Due to uncertainty on the monetary threshold per QALY, alternative values ranging from $€ 0$ to $€ 80000$ were used in the cost-utility analysis. ${ }^{36}$ Since the value that society might place on a unit reduction in BDI-II depression score is unknown, its net benefit cannot be defined. ${ }^{11}$

Bootstrap analyses were carried out using Microsoft Office Excel 2003. All other analyses were carried out using SPSS version 15.0.1 for Windows.

\section{Results}

\section{Population}

Of the 303 eligible participants, 100 were assigned to CCBT, 103 to TAU, and 100 to CCBT plus TAU. After imputation of intermittent missing data, data were available for 275 participants (91\%) at 6 months (CCBT $n=91$, TAU $n=92$, CCBT plus TAU $n=92$ ) and 267 participants $(88 \%)$ at 12 months after baseline (CCBT $n=88$, TAU $n=91$, CCBT plus TAU $n=88$ ). Baseline characteristics of patients lost to follow-up did not differ from participants who completed all assessments. ${ }^{12}$

Table 1 shows the baseline characteristics of all participants, stratified according to intervention group. The CCBT plus TAU group had lower costs for all cost categories compared with both CCBT and TAU. The TAU group showed highest costs on productivity loss, and consequently has higher total costs compared with both CCBT and CCBT plus TAU. The CCBT group had higher baseline healthcare costs and patient and family costs compared with the other groups.

\section{Costs}

The mean volumes of healthcare use and productivity loss per participant are presented in online Table DS1. The uncorrected costs are shown in Table 2. Societal costs over the 12-month follow-up period were lowest for the CCBT group with €9457,

Table 1 Baseline characteristics of the sample and group differences $(n=303)^{\text {a }}$

\begin{tabular}{|c|c|c|c|}
\hline Variable & CCBT $(n=100)$ & CCBT plus TAU $(n=100)$ & $\operatorname{TAU}(n=103)$ \\
\hline Gender, male: $n$ (\%) & $48(48.0)$ & $37(37.0)$ & $46(44.7)$ \\
\hline Age, years: mean (s.d.) & $44.3(11.8)$ & $45.2(10.9)$ & $45.1(12.2)$ \\
\hline \multicolumn{4}{|l|}{ Education, ${ }^{\mathrm{b}} \mathrm{n}(\%)$} \\
\hline LoW & $18(18.6)$ & $17(17.5)$ & $16(16.2)$ \\
\hline Medium & $55(56.7)$ & $52(53.6)$ & $55(55.6)$ \\
\hline High & $24(24.7)$ & $28(28.9)$ & $28(28.3)$ \\
\hline Partner, yes: ${ }^{c} n(\%)$ & 72 (73.5) & $71(73.2)$ & 73 (72.3) \\
\hline Paid job, yes: $n(\%)$ & $53(53.0)$ & $63(63.0)$ & $68(66.0)$ \\
\hline Depressive severity (BDI-II range 0-63), mean (s.d.) & $28.2(7.7)$ & $27.4(8.2)$ & $27.9(7.5)$ \\
\hline \multicolumn{4}{|l|}{ Quality of life, mean (s.d.) } \\
\hline EQ-5D, UK Dolan tariff (range -0.59 to 1 ) & $0.70(0.21)$ & $0.69(0.22)$ & $0.71(0.20)$ \\
\hline EQ-5D, NL Lamers tariff (range -0.33 to 1 ) & $0.70(0.20)$ & $0.69(0.20)$ & $0.71(0.18)$ \\
\hline SF-6D, UK Brazier tariff (range 0.30 to 1 ) & $0.67(0.08)$ & $0.66(0.09)$ & $0.67(0.08)$ \\
\hline \multicolumn{4}{|l|}{ Costs, ${ }^{d}$ mean $(95 \% \mathrm{Cl})$} \\
\hline Healthcare costs ${ }^{\mathrm{e}}$ & $464(270-731)$ & $268(191-353)$ & $345(246-459)$ \\
\hline Patient and family costs ${ }^{\mathrm{e}}$ & $165(85-256)$ & $66(35-101)$ & $77(31-136)$ \\
\hline Productivity costs ${ }^{\mathrm{e}}$ & $2010(1375-2729)$ & $1954(1351-2605)$ & 2501 (1879-3169) \\
\hline Societal costs ${ }^{\mathrm{e}}$ & $2640(1963-3402)$ & $2288(1702-2916)$ & $2922(2300-3568)$ \\
\hline \multicolumn{4}{|c|}{$\begin{array}{l}\text { CCBT, computerised cognitive-behavioural therapy; TAU, treatment as usual by a general practitioner; CCBT plus TAU, combined treatment of both CCBT and TAU; BDI-II, Beck } \\
\text { Depression Inventory II. } \\
\text { a. Analysis of the characteristics costs of all participants, excluding those who dropped out, from research questionnaires (CCBT } n=88, T A U n=91, \text { CCBT plus TAU } n=88 \text { ) revealec } \\
\text { similar results. } \\
\text { b. Data unavailable for } 3 \text { people in the CCBT group, } 4 \text { people in the TAU group, and } 3 \text { people in the CCBT plus TAU group. } \\
\text { c. Data unavailable for } 2 \text { people in the CCBT group, } 2 \text { people in the TAU group, and } 3 \text { people in the CCBT plus TAU group. } \\
\text { d. Presented costs are costs over a 3-month period. } \\
\text { e. The upper and lower confidence limits are the } 2.5 \text { th and } 97.5 \text { th percentile based on } 5000 \text { bootstrap replications. }\end{array}$} \\
\hline
\end{tabular}




\begin{tabular}{|c|c|c|c|}
\hline \multirow[b]{2}{*}{ Cost type } & \multicolumn{3}{|c|}{ Mean per group $(95 \% \mathrm{Cl})^{\mathrm{a}}$} \\
\hline & CCBT $(n=88)$ & CCBT plus TAU $(n=88)$ & $\operatorname{TAU}(n=91)$ \\
\hline Healthcare costs & $1428(1121-1763)$ & 1829 (1429-2261) & 1912 (1515-2349) \\
\hline General practitioner care & 233 & 239 & 265 \\
\hline Mental healthcare specialist & 329 & 401 & 474 \\
\hline Colour Your Life program & 41 & 40 & 0 \\
\hline Paramedical care & 68 & 97 & 106 \\
\hline Medical specialist care & 264 & 422 & 328 \\
\hline Hospital care & 88 & 189 & 293 \\
\hline Antidepressants & 12 & 38 & 51 \\
\hline Other prescribed and OTC medication & 261 & 215 & 193 \\
\hline Paid home care & 47 & 84 & 137 \\
\hline Alternative healers & 78 & 100 & 63 \\
\hline Other care & 6 & 2 & 3 \\
\hline Patient and family costs & $553(321-834)$ & $539(284-859)$ & $408(236-634)$ \\
\hline Travelling & 3 & 3 & 3 \\
\hline Lost time & 39 & 46 & 53 \\
\hline Informal care & 511 & 489 & 352 \\
\hline Productivity costs & 7475 (5556-9430) & 8425 (6063-10 940) & 8925 (6777-11007) \\
\hline Absenteeism & 693 & 605 & 379 \\
\hline Presenteeism & 6782 & 7820 & 8546 \\
\hline Societal costs & 9457 (7547-11506) & 10793 (8412-13328) & 11244 (9206-13419) \\
\hline
\end{tabular}

$€ 10793$ for the CCBT plus TAU group and $€ 11244$ for TAU. Bootstrap replications revealed a mean difference in societal costs in favour of CCBT of $€ 1784$ when compared with TAU and $€ 1340$ compared with CCBT plus TAU. Both healthcare costs and productivity costs were lowest in the CCBT group ( $€ 1428$ and $€ 7475$ respectively) and highest in the TAU group (€1912 and $€ 8925$ respectively). On the other hand, patient and family costs were highest in the CCBT group (€553) and lowest in the TAU group (€408). The CCBT plus TAU group held an intermediate position on all cost categories with $€ 1829$ healthcare costs, $€ 8425$ productivity costs and $€ 539$ patient and family costs. About $80 \%$ of the societal costs consisted of costs resulting from productivity loss.

Table 3 shows the mean costs per participant group for the different cost scenarios used in the base-case and sensitivity analyses. In all scenarios, CCBT has the lowest mean costs per participant. In the base-case analysis, costs are corrected for baseline cost differences. After regression correction for baseline differences, CCBT has the lowest societal costs during the 6-month (€4462) and 12-month (€9092) follow-up period. After 6 months the mean societal costs of TAU (€5113) are a little higher compared with the costs of CCBT plus TAU (€5069). However, after 12 months, CCBT plus TAU has the highest costs $(€ 10534)$, whereas TAU held an intermediate cost position (€9765) between CCBT plus TAU and CCBT. As shown in Table 3, varying the costs of Colour Your Life or the valuation method of the productivity costs resulted in only minor changes in costs and in differences in costs between the participant groups. Varying the cost perspective from the societal to the healthcare costs suggests that the TAU group has highest baseline corrected costs ( $€ 1861)$, whereas the costs of the CCBT plus TAU group are a bit lower $(€ 1797)$ and CCBT shows the lowest costs (€1366).

In the sensitivity analyses without correction for the baseline costs, the CCBT group remains the group of participants with the lowest costs in all cost-varying scenarios, whereas TAU shows highest costs in all scenarios.

\section{Effects}

Table 4 reports no significant group differences in QALYs or clinical effectiveness outcomes. In the base-case analysis (baseline regression-corrected QALY using the UK tariff to value the EQ-5D), results show a mean QALY of 0.71 for CCBT, 0.71 for CCBT plus TAU, and 0.72 for TAU. The mean QALY outcomes in all three participant groups remain about 0.70 , regardless of using a baseline correction or the type of QALY measure used. There does not seem to be much improvement in terms of quality of life, as the mean QALYs during the 12-month follow-up period are very similar to the mean baseline utilities of about 0.70 per participant group.

The clinical effectiveness outcome does show an improvement during the 6- and 12-month follow-up period in all three participant groups. However, these improvements in effectiveness outcomes are rather minor improvements in depression. ${ }^{12}$

\section{Comparing costs and effects}

Figure 1 presents the cost-effectiveness acceptability curve of the base-case cost-utility analysis with the bootstrapped baseline-corrected societal costs and EQ-5D-based QALYs. Computerised CBT tends to be the most optimal treatment compared with both TAU and CCBT plus TAU with a probability of about $65 \%$ of being the most efficient strategy at a threshold value of $€ 0$ per QALY, but diminishing towards a $40 \%$ probability when increasing the threshold value up to $€ 80000$. Despite the $25 \%$ probability of TAU being the most efficient strategy at a threshold value of $€ 0$ per QALY, its probability increases up to about $40 \%$ when society's willingness to pay increases up to $€ 80000$ per QALY, and consequently the choice between TAU and CCBT becomes almost indifferent at a threshold of $€ 80000$. The CCBT plus TAU treatment has the lowest chance of being the most efficient strategy, with probabilities varying from 10 to $20 \%$ at the presented threshold values per QALY.

Figure 2 shows the cost-effectiveness acceptability curve for the base-case cost-effectiveness analysis at 12-month follow-up 


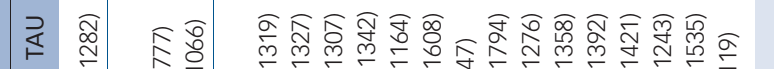

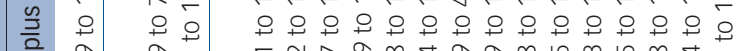
长

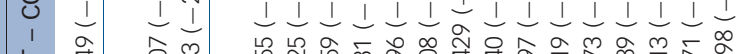

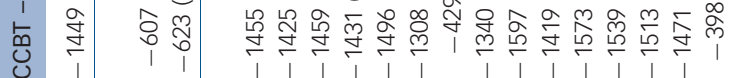
$\stackrel{\Xi}{0}$

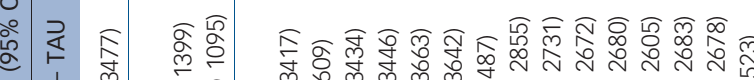

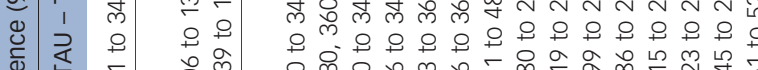

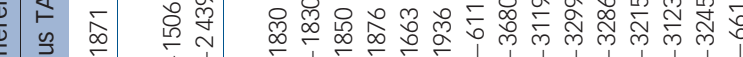

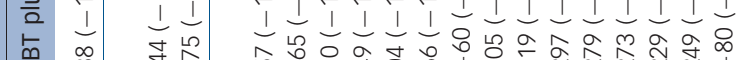

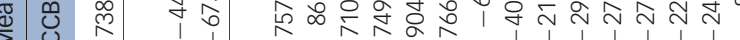

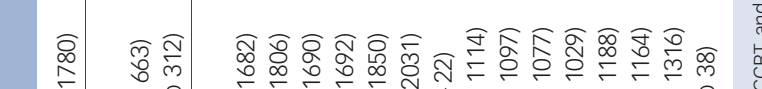
₹

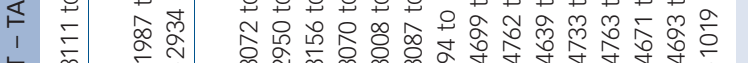
t⿹

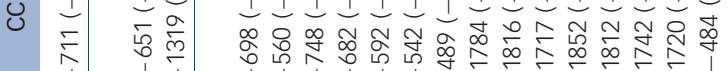

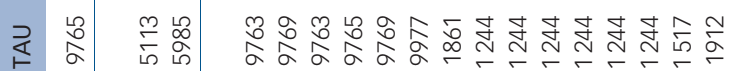
읗

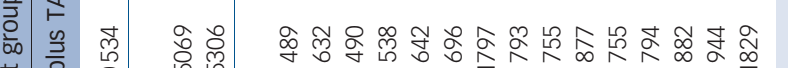

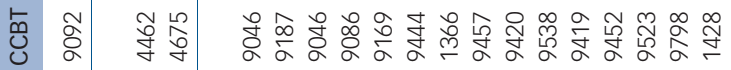

こ

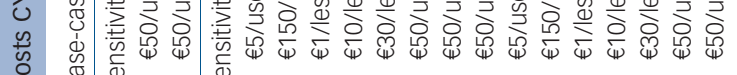

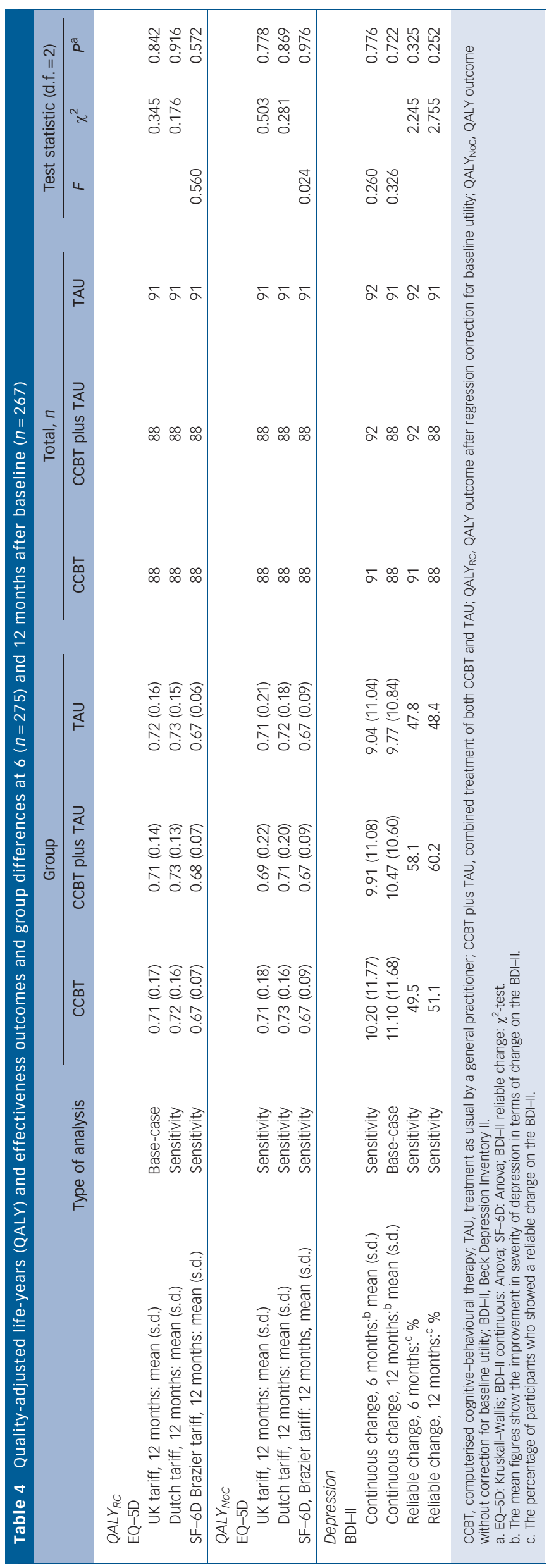




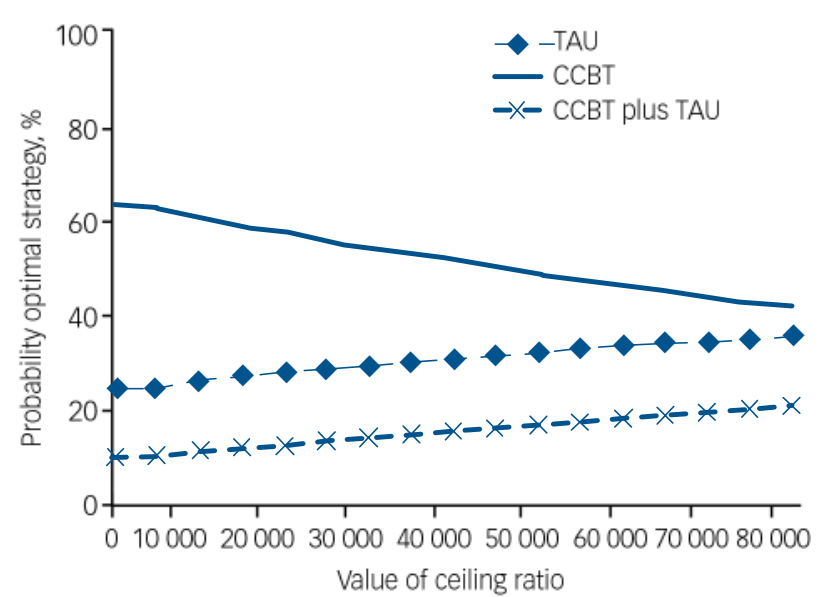

Fig. 1 Base-case analysis. Cost-effectiveness acceptability curves of the cost-utility at 12-month follow-up.

CCBT, computerised cognitive-behavioural therapy; TAU, treatment as usual by a general practitioner; CCBT plus TAU combined treatment of both CCBT and TAU. Costs: societal costs after regression correction for baseline costs; utility: qualityadjusted life-year (EQ-5D, UK tariff) after regression correction for baseline utilities.

using point changes on the BDI-II scale as outcome. As there is no guideline on the threshold value per point improvement on the BDI-II, the value of the ceiling ratio is varied up to an amount of $€ 40000$ where the probabilities per treatment remain rather stable for higher thresholds. The CCBT treatment shows the highest probabilities, of about $60 \%$, of being the most efficient strategy, regardless of the threshold value for an improvement on the BDI-II scale. If one is willing to pay at least $€ 5000$ per point improvement on the BDI-II scale, the TAU treatment is less favoured with probabilities of about $10 \%$ of being the most optimal strategy, whereas CCBT plus TAU shows probabilities of about $30 \%$. Below the threshold value of $€ 5000$, TAU has a probability of between 13 to $25 \%$, whereas the CCBT plus TAU treatment shows increasing probabilities of about 10 to $20 \%$.

\section{Sensitivity analyses}

Varying the outcome parameter of the base-case cost-utility scenario to either the regression-corrected QALY valued by the Dutch EQ-5D tariff or the SF-6D revealed similar results. Varying the regression-corrected societal costs by different cost calculations of Colour Your Life, or the productivity costs to the human capital approach, did not show much difference from the base-case analysis with QALY as outcome measure. Computerised CBT is still the most favourable treatment in terms of cost-utility. However, as a consequence of not using baseline corrections, the TAU treatment turns out to have the lowest probability of being the most optimal choice. In this scenario, CCBT has a 70 to $80 \%$ probability of being the most efficient treatment given the varying threshold values up to $€ 80000$, whereas CCBT plus TAU, and TAU each have a probability about $10-20 \%$.

The sensitivity analysis with most deviation from the base-case cost-utility analysis is the scenario in which the healthcare cost perspective is used. Figure 3 shows CCBT is the most efficient strategy for treatment at the lower threshold values. But when increasing the ceiling on the value per QALY, the choice between the three treatment strategies becomes indifferent as all curves approach a probability of $30 \%$.

When using clinical effectiveness as an outcome measure, most of the sensitivity analyses resulted in minor differences from the cost-effectiveness acceptability curves of the base-case analysis

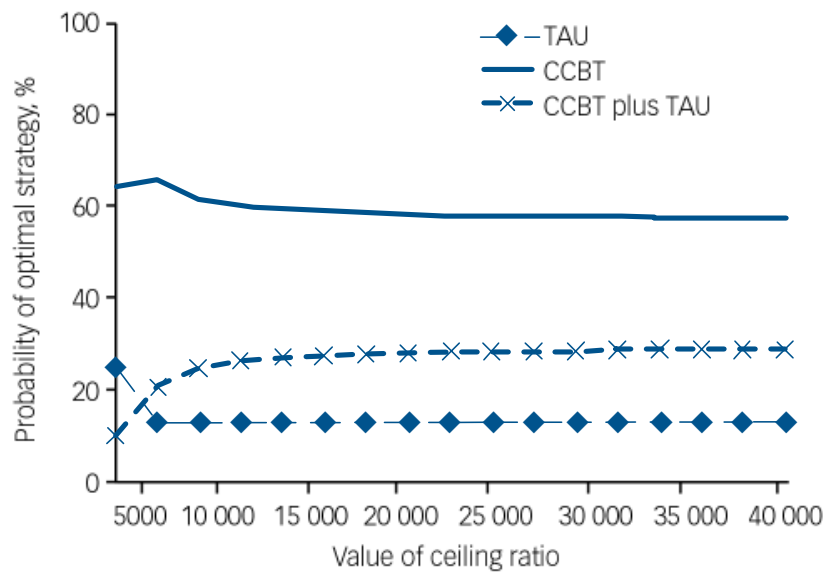

Fig. 2 Base-case analysis. Cost-effectiveness acceptability curves of the cost-effectiveness at 12-month follow-up.

CCBT, computerised cognitive-behavioural therapy; TAU, treatment as usual by a general practitioner; CCBT plus TAU combined treatment of both CCBT and TAU. costs: societal costs after regression correction for baseline costs; effectiveness: points improvement on the Beck Depression Inventory II.

at 12-month follow-up. The variations in societal cost calculation by using different cost for Colour Your Life, varying the productivity costs to the human capital approach, varying the use of baseline corrected costs, varying the cost perspective to the healthcare perspective or varying the time period by a 6-month time period resulted in similar cost-effectiveness acceptability curves as the base-case analysis at 12-month follow-up. Only varying the outcome measure into the reliable change index of the BDI-II showed differences from the base-case analysis in which costs were related to the absolute change on the BDI-II. As presented in Fig. 4, CCBT is still the favoured treatment at the lower threshold values. However, the curve of CCBT plus TAU shows a steeper increase. From a threshold value of $€ 7000$ onwards, CCBT plus TAU outperforms CCBT up to an $80 \%$ chance of being the most optimal strategy, whereas CCBT decreases to $20 \%$ at higher threshold values for an individual with a reliable BDI-II change.

\section{Discussion}

\section{Main results}

At first glance, CCBT seems to be the most efficient treatment strategy, since in most cost-effectiveness and cost-utility scenarios CCBT has the highest probability of being the most optimal treatment choice.

In all cost-utility analyses, the CCBT treatment turned out to be the most efficient strategy for treatment. The mean societal costs were lowest in this group, and cost-utility cost-effectiveness acceptability curves showed that CCBT has the highest probability of being the most efficient treatment strategy compared with both TAU and CCBT plus TAU. However, when increasing the threshold value for an additional QALY, the difference between CCBT $v$. TAU and CCBT plus TAU decreases and in some analyses tends to indifference in the choice between the three treatments in terms of cost-utility.

With probabilities of about $60 \%$ of CCBT being the most efficient treatment choice, the cost-effectiveness analysis using the absolute change on the BDI-II also shows a preference for the CCBT treatment $v$. both TAU and CCBT plus TAU. However, when evaluating the reliable change on the BDI-II, 


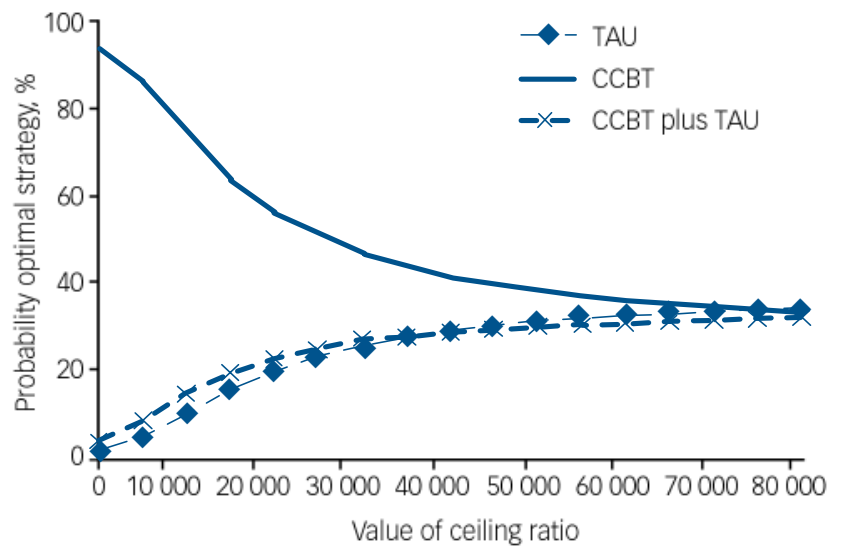

Fig. 3 Sensitivity analysis. Cost-effectiveness acceptability curves of the cost-utility with healthcare costs at 12-month follow-up.

CCBT, computerised cognitive-behavioural therapy; TAU, treatment as usual by a general practitioner; CCBT plus TAU combined treatment of both CCBT and TAU. Costs: healthcare costs after regression correction for baseline costs; utility: quality-adjusted life-year (EQ-5D, UK tariff) after regression correction for baseline utilities.

the CCBT plus TAU treatment outperforms CCBT at threshold values above $€ 7000$ per participant achieving reliable change.

Despite the outcomes of the economic evaluation, there are no statistically significant differences in effectiveness or QALY outcomes, and all three treatments do not seem to achieve much improvement in depression or quality of life during the 12-month follow-up period. However, changing the BDI-II outcome from absolute change to reliable change does have an impact on the cost-effectiveness outcomes. Whereas the BDI-II decreases on average about 10 points per participant in all groups, using the cut-off score of 9 for the reliable change results in $60 \%$ for the CCBT plus TAU group with reliable change, compared with about $51 \%$ in the CCBT group and $48 \%$ in the TAU group. Although not significant, this difference in reliable change on the BDI-II does seem to be relevant and in favour of the CCBT plus TAU treatment. Given the high depressive severity of our sample, the differences in reliable change on the BDI-II might not seem surprising. For people with more severe depression, combination treatments have been found to be superior to single treatments. ${ }^{37,38}$

\section{Previous studies}

Until now, only one study has been published on the costeffectiveness of CCBT for depression. McCrone et $_{\text {al }}{ }^{11}$ performed a randomised trial in which supported CCBT was compared with usual care for anxiety and depression. In their study, the healthcare costs of CCBT were a little higher when compared with the healthcare costs of TAU, whereas our study showed the reverse. This might be explained by differences in the type of intervention. In McCrone's study, the CCBT program was supported and took place at the GP practice, consequently involving greater healthcare costs. In our study, the productivity costs of CCBT were lower compared with those of TAU, resulting in TAU being more expensive compared with CCBT.

Contrary to our study, CCBT was clinically superior to TAU and showed higher effect sizes in the McCrone study. ${ }^{11,12}$ McCrone and colleagues found that if society is willing to pay only a small amount for increased effectiveness, CCBT has a higher chance of being cost-effective compared with the TAU treatment.

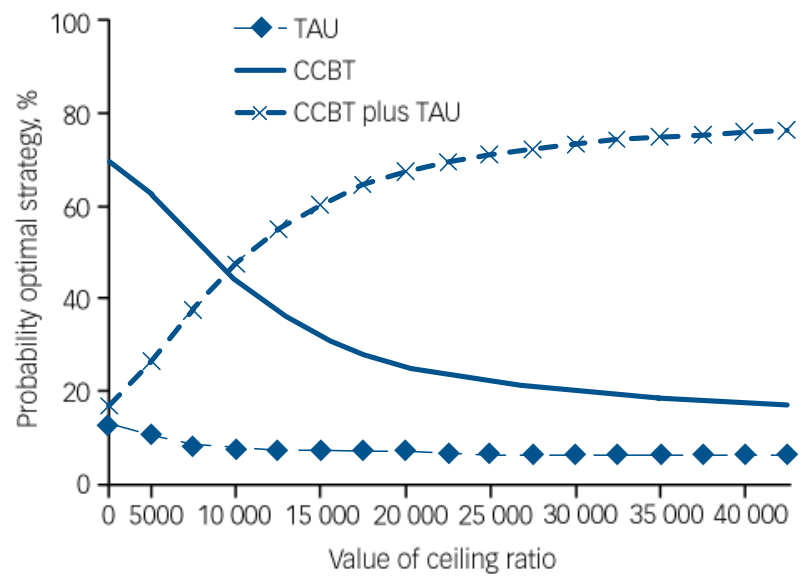

Fig. 4 Sensitivity analysis. Cost-effectiveness acceptability curves of the reliable change on the Beck Depression Inventory II at 12 months.

CCBT, computerised cognitive-behavioural therapy; TAU, treatment as usual by a general proctitioner; CCBT plus TAU combined treatment of both CCBT general practitioner; CCBT pluS TAU combined treatment of both CCBT and TAU. reliable change (i.e. 9 points improvement) on the Beck Depression Inventory II.
Both McCrone's and our study thus seem to be in favour of the CCBT treatment $v$. TAU in terms of cost-effectiveness.

\section{Methodological considerations}

In this study, we made several assumptions about the calculation and valuation of costs. First of all, the costs for Colour Your Life are estimates based on the actual costs of the program, and we decided to calculate costs only for those participants who logged onto the program at least once. Different views on our calculation of Colour Your Life costs per participant might exist. On the one hand, one might expect that a participant will have to pay for using the program, or for the time duration of using the program. On the other hand, one might also argue that in real life a participant would have to pay for receiving a login code for the program, regardless of their use of Colour Your Life. Moreover, the time costs of individuals who followed Colour Your Life might have been underestimated. The time spent on Colour Your Life was based on the computer-registered login time, and does not include the time a patient might have spent reflecting on the lessons' content or doing homework tasks offline. On the other hand, the computer registrations might possibly give an overestimation of time spent on Colour Your Life as the individual might be carrying out other tasks during the time logged onto the program. Moreover, we opted not to include the costs of a computer and/or internet access. The reason for this is that participants included in the trial had to have a computer at home with a broad-band internet connection. Consequently, participating in the Colour Your Life program should not lead to any additional expenditure on computers or the internet. However, this also means that our study sample is limited to the population of internet and computer users.

In the recording of cost data, one important difference is that the costs of Colour Your Life are based on computer-registered data, whereas costs of other healthcare items are based on patient-reported care consumption. The latter method might have lead to over- or underestimations of healthcare use, as self-reports by participants can be vulnerable to recall error. ${ }^{39}$

In the base-case analysis, we used regression correction for the baseline costs and QALYs. Although utilities did not differ 
significantly among the groups of participants, it is likely that the participant's baseline utility is highly correlated with the QALY outcome. As argued by Manca et $a l,{ }^{32}$ controlling for baseline utility should be standard practice in economic evaluations. As shown in our sensitivity analyses, the baseline correction did affect the outcomes of the costs, cost-effectiveness and cost-utility analyses. In the base-case analysis, the CCBT plus TAU group is the one with highest costs during the 12-month follow-up (CCBT plus TAU €10 534; TAU €9765; CCBT €9092), whereas in the sensitivity analysis without correction, it is the TAU treatment that shows the highest mean societal costs per individual (TAU $€ 11$ 244; CCBT plus TAU €10 793; CCBT €9457). Although CCBT remained the treatment with the highest probability of being most cost-effective, its probability in the base-case cost-utility analysis was much lower (about 40-65\%) than in the sensitivity cost-utility analysis without correction (70-80\%). The TAU group has a probability of about $25-40 \%$ in the base-case cost-utility analysis, whereas in the sensitivity analysis its probability is only about $10-20 \%$. These differences in corrected $v$. uncorrected costs and outcomes stress the importance of taking baseline outcomes into account in economic evaluations.

Evaluating the cost-effectiveness based on reliable change outcomes shows that CCBT plus TAU outperforms CCBT from a certain point onwards. However, these outcomes should be considered with caution, as power calculations of the sample size were based on a mean difference in change scores of 5 on the BDI-II. ${ }^{14}$ The reliable change outcome refers to a change of 9 points on the BDI-II to be able to find reliable differences between the intervention groups, and a larger sample size might be required.

In our cost-utility analysis, we interpreted the results at varying monetary threshold values of a QALY up to $€ 80000$. However, the exact threshold value is unknown, and there are no exact guidelines available in the Netherlands. Several studies on the threshold suggested varying values, although in general $€ 18000$ is accepted as the threshold value per QALY for preventive care in the Netherlands. However, the Dutch Council for Public Health and Health Care recommends relating the threshold of the costs of a QALY to the burden of disease, with a limit of $€ 80000$ per QALY for diseases with a maximum loss in health status. ${ }^{36}$ Despite the absence of clear guidelines, we assume that the chosen range of cost-utility thresholds in our study is broad enough to capture the relevant threshold values.

A last remark concerns the scope of costs included in the analysis. Because of the broad impact depression can have on an individual's life, we chose to include all health-related healthcare, productivity and patient and family costs in the analysis. However, since the costs are not limited to depression-related costs, resulting costs are probably an overestimation of the costs resulting from depression.

Despite the assumptions mentioned above, we believe that one of the strengths of our study is that the main findings were rather robust. In the sensitivity analyses, we tried to capture the uncertainty in the assumptions. Both the base-case analysis and the sensitivity cost-utility analyses indicated a preference for CCBT at a considerable range of cost-effectiveness and cost-utility thresholds.

\section{Implications of the study characteristics}

In our sample, the adherence to treatment as well as the clinical effectiveness and change in quality of life were rather low. ${ }^{12}$ In this study, there was not a control group receiving no care. One of the questions is whether the changes in clinical effectiveness or quality of life of our participants can be attributed to the treatment received - especially given the low adherence rates - or whether they reflect the natural course of depression. In the absence of a no-treatment group, it is not clear whether the participants' depression and QALY changes differ from people with depression who do not receive treatment during a 12-month follow-up period. The low adherence to treatment could explain the small differences in costs between the three treatment groups. Possible explanations for the low effect of treatment and the low adherence rate have been suggested elsewhere. ${ }^{12}$

Moreover, BDI-II scores at baseline in our sample were higher than generally seen in people with depression in primary care. ${ }^{40}$ The interventions offered in our study might have been less suited to this patient group. A more intensive and/or supported treatment form might have been justified for this population, and might have generated better outcomes in terms of QALY and clinical effectiveness.

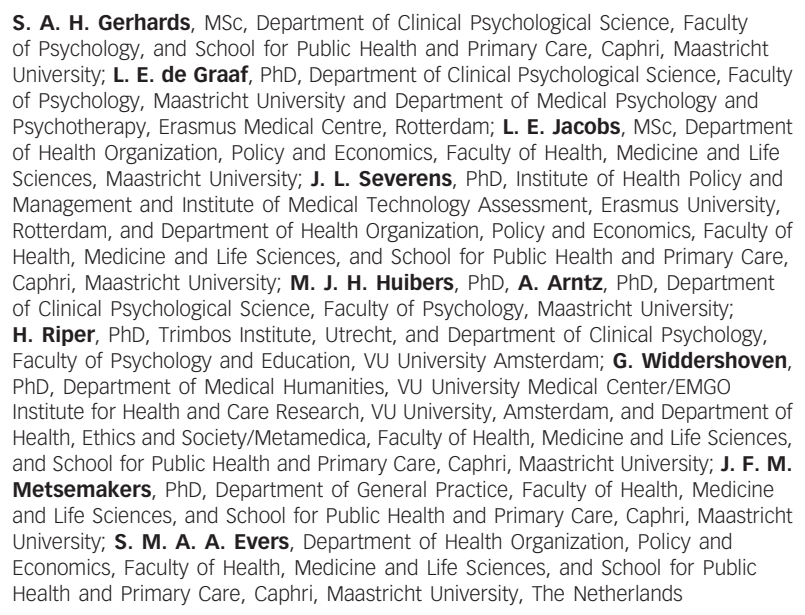

S. A. H. Gerhards, MSc, Department of Clinical Psychological Science, Faculty of Psychology, and School for Public Health and Primary Care, Caphri, Maastricht University; L. E. de Graaf, PhD, Department of Clinical Psychological Science, Faculty of Psychology, Maastricht University and Department of Medical Psychology and Psychotherapy, Erasmus Medical Centre, Rotterdam; L. E. Jacobs, MSc, Department of Health Organization, Policy and Economics, Faculty of Health, Medicine and Life Sciences, Maastricht University; J. L. Severens, PhD, Institute of Health Policy and Management and Institute of Medical Technology Assessment, Erasmus University, Rotterdam, and Department of Health Organization, Policy and Economics, Faculty of Health, Medicine and Life Sciences, and School for Public Health and Primary Care, Caphri, Maastricht University; M. J. H. Huibers, PhD, A. Arntz, PhD, Department of Clinical Psychological Science, Faculty of Psychology, Maastricht University; H. Riper, PhD, Trimbos Institute, Utrecht, and Department of Clinical Psychology, Faculty of Psychology and Education, VU University Amsterdam; G. Widdershoven PhD, Department of Medical Humanities, VU University Medical Center/EMGO Institute for Health and Care Research, VU University, Amsterdam, and Department of Health, Ethics and Society/Metamedica, Faculty of Health, Medicine and Life Sciences, and School for Public Health and Primary Care, Caphri, Maastricht University; J. F. M. Metsemakers, PhD, Department of General Practice, Faculty of Health, Medicine and Life Sciences, and School for Public Health and Primary Care, Caphri, Maastricht University; S. M. A. A. Evers, Department of Health Organization, Policy and Economics, Faculty of Health, Medicine and Life Sciences, and School for Public Health and Primary Care, Caphri, Maastricht University, The Netherlands

Correspondence: S. A. H. Gerhards, Department of Clinical Psychological Science, Maastricht University, P.O. Box 616, 6200 MD Maastricht, The Netherlands. Email: S.Gerhards@maastrichtuniversity.n

First received 4 Mar 2009, final revision 5 Oct 2009, accepted 28 Oct 2009

\section{Funding}

The trial is financed by ZonMw (Netherlands Organisation for Health Research and Development; project number 945-04-417), Research Institute EPP and Research Institute CAPHRI. Municipalities Eijsden, Meerssen, Sittard-Geleen, Valkenburg and Maastricht sponsored the study.

\section{Acknowledgements}

We thank Annie Hendriks and Greet Kellens for their assistance during the study and Rosanne Janssen for the development of the infrastructure for online data collection. Thanks to Fons Kessels, Thea van Asselt, Frenk Peeters, John Pletzers, Filip Smit, Marc Koopmanschap and Jorne Grolleman for their help on specific questions.

\section{References}

1 Bijl RV, Ravelli A, van Zessen G. Prevalence of psychiatric disorder in the general population: results of the Netherlands Mental Health Survey and Incidence Study (NEMESIS). Soc Psychiatry Psychiatr Epidemiol 1998; 33 : 587-95.

2 Bijl RV, Ravelli A. Current and residual functional disability associated with psychopathology: findings from the Netherlands Mental Health Survey and Incidence Study (NEMESIS). Psychol Med 2000; 30: 657-68.

3 Kruijshaar ME, Hoeymans N, Bijl RV, Spijker J, Essink-Bot ML. Levels of disability in major depression. Findings from the Netherlands Mental Health Survey and Incidence Study (NEMESIS). J Affect Disord 2003; 77: 53-64.

4 Sobocki P, Jönsson B, Angst J, Rehnberg C. Cost of depression in Europe. J Ment Health Policy Econ 2006; 9: 87-98. 
5 Kendrick T, Chatwin J, Dowrick C, Tuylee A, Moriss R, Peveler R, et al. Randomised controlled trial to determine the clinical effectiveness and costeffectiveness of selective serotonin reuptake inhibitors plus supportive care versus supportive care alone, for mild to moderate depression with somatic symptoms in primary care: the THREAD (THREshold for AntiDepressant response) study. Health Technol Assess 2009; 13: 1-159.

6 Butler AC, Chapman JE, Forman EM, Beck AT. The empirical status of cognitive-behavioral therapy: a review of meta-analyses. Clin Psychol Rev 2006; 26: 17-31.

7 Hollon SD, Stewart MO, Strunk D. Enduring effects for cognitive behavior therapy in the treatment of depression and anxiety. Annu Rev Psychol 2006 57: $285-315$.

8 Hirschfeld RM, Keller MB, Panico S, Arons BS, Barlow D, Davidoff F, et al. The National Depressive and Manic-Depressive Association consensus statement on the undertreatment of depression. JAMA 1997; 277: 333-40.

9 Kaltenthaler E, Brazier J, De Nigris E, Tumur I, Ferriter M, Beverly C, et al. Computerised cognitive behaviour therapy for depression and anxiety update: a systematic review and economic evaluation. Health Technol Assess 2006; 10: 1-186.

10 National Institute for Health and Clinical Excellence. Computerised Cognitive Behaviour Therapy for Depression and Anxiety. Review of Technology Appraisal 51. NICE, 2006

11 McCrone P, Knapp M, Proudfoot J, Ryden C, Cavanagh K, Shapiro DA, et al. Cost-effectiveness of computerised cognitive-behavioural therapy for anxiety and depression in primary care: randomised controlled trial. Br J Psychiatry 2004; 185: 55-62.

12 de Graaf LE, Gerhards SAH, Arntz A, Riper H, Metsemakers JFM, Evers SMAA et al. Clinical effectiveness of online computerised cognitive-behavioural therapy without support for depression in primary care: randomised trial. Br J Psychiatry 2009; 195: 73-80.

13 Van der Does AJW. De Nederlandse versie van de Beck Depression Inventory - second edition (BDI-II-NL): Handleiding (in Dutch) [The Dutch Version of the Beck Depression Inventory - Second Edition (BDI-II-NL): A Manual]. The Psychological Corporation, 2002

14 de Graaf LE, Gerhards SAH, Evers SMAA, Arntz AR, Riper H, Severens JL, et al. Clinical and cost-effectiveness of computerised cognitive behavioural therapy for depression in primary care: design of a randomised trial. BMC Public Health 2008; 8: 224 .

15 СвО. Multidisciplinaire Richtlijn Depressie: Richtlijn voor de Diagnostiek en Behandeling van Volwassen Cliënten met een Depressie [Multidisciplinary Guideline Depression: Guideline for Diagnostics and Treatment of Adult Depression Clients]. Trimbos-instituut, 2005.

16 Nederlands Huisartsen Genootschap. NHG-Standaard Depressieve Stoornis (Depressie) [Dutch College of General Practitioners - Practice guidelines depressive disorder (depression)]. Nederlands Huisartsen Genootschap, 2003

17 Drummond MF, Sculpher MJ, Torrance GW, O’Brien B, Stoddart GL. Methods for the Economic Evaluation of Health Care Programmes. Oxford University Press, 2005.

18 Oostenbrink JB, Bouwmans CAM, Koopmanschap MA, Rutten FFH. Handleiding voor Kostenonderzoek: Methoden enStandaard Kostprijzen voor Economische Evaluaties in de Gezondheidszorg (Geactualiseerde versie 2004) [Dutch Manual for Costing: Methods and Standard Costs for Economic Evaluations in Health Care (actualized version 2004)]. College voo Zorgverzekeringen, 2004

19 Koopmanschap M, Meerding WJ, Evers S, Severens J, Burdorf A, Brouwer W. Handleiding voor het gebruik van PRODISO versie 2.1 [Manual for the Use of PRODISQ version 2.1]. Erasmus MC - Instituut voor Medical Technology Assessment, Instituut Maatschappelijke Gezondheidszorg, Universiteit van Maastricht - Beleid Economie en Organisatie van de Zorg, 2004.
20 Koopmanschap MA, Rutten FFH, van Ineveld BM, van Roijen L. The friction cost method for estimating the indirect costs of disease. J Health Econ 1995; 14: $171-89$

21 College voor Zorgverzekeringen. Farmacotherapeutisch Kompas 2008 [Pharmacotherapeutic Compass 2008]. College voor Zorgverzekeringen, 2007.

22 Beck AT, Steer RA, Ball R, Ranieri WF. Comparison of Beck Depression Inventories-IA and -II in psychiatric outpatients. J Pers Assess 1996; 67: 588-97.

23 Arnau RC, Meagher MW, Norris MP, Bramson R. Psychometric evaluation of the Beck Depression Inventory-II with primary care medical patients. Health Psychol 2001; 20: 112-9.

24 EuroQol Group. EuroQol - a new facility for the measurement of healthrelated quality of life. Health Policy 1990; 16: 199-208.

25 Brazier J, Usherwood T, Harper R, Thomas K. Deriving a preference-based single index from the UK SF-36 Health Survey. J Clin Epidemiol 1998; 51 1115-28

26 Dolan P. Modeling valuations for EuroQol health states. Med Care 1997; 35 1095-108.

27 Lamers LM, McDonnell J, Stalmeier PFM, Krabbe PFM, Busschbach JJV. The Dutch tariff: results and arguments for an effective design for national EQ-5D valuation studies. Health Econ 2006; 15: 1121-32.

28 Brazier J, Roberts J, Deverill M. The estimation of a preference-based measure of health from the SF-36. J Health Econ 2002; 21: 271-92.

29 Brazier JE, Roberts J. The estimation of a preference-based measure of health from the SF-12. Med Care 2004; 42: 851-9.

30 Briggs $A H$, Wonderling DE, Mooney CZ. Pulling cost-effectiveness analysis up by its bootstraps: a non-parametric approach to confidence interval estimation. Health Econ 1997; 6: 405-15.

31 van Asselt ADI, van Mastrigt GAPG, Dirksen CD, Arntz A, Severens JL, Kessels AGH. How to deal with cost differences at baseline. Pharmacoeconomics 2009; 27: 519-28.

32 Manca A, Hawkins N, Sculpher MJ. Estimating mean QALYs in trial-based cost-effectiveness analysis: the importance of controlling for baseline utility. Health Econ 2005; 14: 487-96.

33 Jacobson NS, Truax P. Clinical significance: a statistical approach to defining meaningful change in psychotherapy research. J Consult Clin Psychol 1991; 59: 12-9.

34 Stinnett AA, Mullahy J. Net health benefits: a new framework for the analysis of uncertainty in cost-effectiveness analysis. Med Decis Making 1998; 20: S68-80

35 Fenwick E, O'Brien BJ, Briggs A. Economic evaluation. Cost-effectiveness acceptability curves - facts, fallacies and frequently asked questions. Health Econ 2004; 13: 405-15.

36 Raad voor de Volksgezondheid en Zorg. Zinnige en Duurzame Zorg [Sensible and Sustainable Care]. Zoetermeer, 2006.

37 Pampallona S, Bollini P, Tibaldi G, Kupelnick B, Munizza C. Combined pharmacotherapy and psychological treatment for depression. Arch Gen Psychiatry 2004; 61: 714-9.

38 Friedman MA, Detweiler-Bedell JB, Leventhal HE, Horne R, Keitner GI, Miller IW. Combined psychotherapy and pharmacotherapy for the treatment of major depressive disorder. Clin Psychol Sci Pract 2004; 11: 47-68.

39 van den Brink $M$, van den Hout WB, Stiggelbout AM, van de Velde $\mathrm{CJH}_{\text {, }}$ Kievit J. Cost measurement in economic evaluations of health care. Whom to ask? Med Care 2004; 42: 740-6.

40 Vuorilehto M, Melartin TK, Rytsälä HJ, Isometsä E. Do characteristics of patients with major depressive disorder differ between primary and psychiatric care? Psychol Med 2007; 37: 893-904. 